\title{
Redox controlled stable chromium isotope fractionation during planetary differentiation
}

JI SHEN $^{1 *}$, LIPING QIN ${ }^{1}$, JIUXING XIA ${ }^{2}$, RICHARD W. CARLSON $^{3}$, SHICHUN HUANG ${ }^{4}$, ROSALIND T. HELZ ${ }^{5}$, TIMOTHY D. MOCK ${ }^{3}$

${ }^{1}$ CAS Key Laboratory and CAS Center for Excellence in Comparative Planetology, University of Science and Technique of China, China (*correspondance: sjlcwqqq@ustc.edu.cn)

${ }^{2}$ Zhejiang University, China

${ }^{3}$ Carnegie Institution for Science, United States

${ }^{4}$ University of Nevada, United States

${ }^{5}$ USGS Volcano Hazards Program VA, United States

The lunar and Vesta basaltic rocks have slightly lighter $\mathrm{Cr}$ isotope compositions than terrestrial basalts, and two processes have been previouly proposed: volatilization loss of oxidized $\mathrm{Cr}$ species during planetary magmatic ocean stage $[1,2]$; and redox-related isotope fractionations during partial melting or crystal fractionation [3]. Our recent work has shown that $\mathrm{Cr}$ isotope fractionation factors between mantle minerals is controlled by oxygen fugacity [4]. Therefore, it is necessary to investigate $\mathrm{Cr}$ isotope behaviors during magma processes and the effect of oxygen fugacity.

In the current study, we analyzed twenty-one wellstudied OIBs from three Hawaiian volcanos: Kilauea, Koolau and Mauna Kea. The homogenous $\delta^{53} \mathrm{Cr}$ of Koolau and Mauna Kea lavas implies that post-magmatic alterations do not significantly change $\mathrm{Cr}$ isotope systems. In contrast, $\delta^{53} \mathrm{Cr}$ of Kilauea Iki basalts vary from $-0.18 \%$ to $0.00 \%$, and are positively correlated to $\mathrm{MgO}$ and $\mathrm{Mg \#}$. This is interpreted as a result of crystallization and accumulation of spinel and olivine during magma differentiation.

Combining these results, we present a quantitative model that relates $\mathrm{Cr}$ isotope compositions of the basaltic rocks from Earth, Moon and Vesta, to the crystallization assemblage, the fractionation degree, and the $\mathrm{Cr}^{2+} / \Sigma \mathrm{Cr}$ ratios of minerals and melts (dominated by $f_{\mathrm{O} 2}$ ). We speculate that the lunar and the Earth's mantle have the same $\mathrm{Cr}$ isotope composition $\left(-0.16 \%\right.$ to $-0.09 \%$ ). The low $\delta^{53} \mathrm{Cr}$ in the lunar mafic rocks is the result of redox-controlled crystal fractionation and accumulation of lunar magma ocean.

[1] Sossi et al. (2018) PNAS, 115, 10920-10925. [2] Zhu et al. (2019) GCA, 266, 598-610. [3] Bonnand et al. (2016) GCA, 175, 208-221. [4] Shen et al. (2018) EPSL, 499, 278290. 